\title{
Evaluation of the Management Results of Uretero-Pelvic Junction Abnormalities
}

\author{
Prince Pascal Hounnasso', Josué Dejinnin Georges Avakoudjo1, \\ Fouad Kolawalé Yde Soumanou1 ${ }^{*}$, Ghislain Honvozo Djidjoho², \\ Michaël Michel Agounkpe1, Gilles Natchagande1, Olivier Dandjlessa1, \\ Magloire Dodji Yevi' ${ }^{2}$ Mamadou Téoulé Traore' ${ }^{1}$, Djamal Jacquet ${ }^{1}$, \\ Viyome Edoe Sewa1, Sosthène Ouedraogo ${ }^{1}$ \\ ${ }^{1}$ Teaching University Hospital (CNHU-HKM) of Cotonou, Cotonou, Benin \\ ${ }^{2}$ Teaching University Hospital (CHD-OP) of Porto-Novo, Porto-Novo, Benin \\ Email: Soumfou@yahoo.fr
}

Received 26 July 2015; accepted 12 September 2015; published 15 September 2015

Copyright (C) 2015 by authors and Scientific Research Publishing Inc.

This work is licensed under the Creative Commons Attribution International License (CC BY). http://creativecommons.org/licenses/by/4.0/

c) (i) Open Access

\begin{abstract}
Objectives: To evaluate therapeutic and prognosis of Uretero-pelvic junction abnomalities. Methods: This article was retrospective and descriptive, covering a period of six months, running from January 1st to December 31st, 2013 and conducted to evaluate therapeutic and prognosis of Uretero-pelvic junction abnormalities. Included criteria were all patients whose diagnosis was abnormalities of the uretero-pelvic junction and had been confirmed after para clinical explorations. The stricture of the junction after a first kidney surgery did not include. The Creatinine level has considered high from $15 \mathrm{mg} / \mathrm{l}$. Results: The median age was 35 years old. Age groups (30 - 40) years old have predominated in $36.2 \%$. A male predominance had been noted in $62.3 \%$ versus $37.7 \%$ women. The most affected occupation was the officials in $37.7 \%$ of cases. The main reason for consultation was lumbar pain in $\mathbf{9 7 . 1 \%}$. The high creatinine level has observed in 19 patients (27.5\%). Sixty-one patients (88.41\%) have been operated. An abstention has been observed in 7 patients (10.14\%) and one patient died before the surgical issue in renal failure. The early postoperative course has been uneventful in $78.7 \%$ (48 cases) and complicated in $21.3 \%$ ( 21 cases). Conclusions: Open surgery tends to disappear at the expense of the endopyelotomy and laparoscopy which gives best results. However, it is still relevant.
\end{abstract}

\section{Keywords}

UJPO, Management, Open Surgery, Early Postoperative

"Corresponding author. 


\section{Introduction}

Uretero-pelvic junction (UPJ) abnomalies are obstructive congenital malformation, anatomical or functional of the ureteropelvic junction. They are most often recognized prenatally and in infancy. They affect the junction between the renal pelvis and the ureter. The most common disease of uropathies discovered in prenatal malformations is the UPJ. Over 3 millions obstetric ultrasounds are performed for discovering 13,000 UPJ each year in the USA [1]. Nowadays open surgery seems to be surpassed by the laparoscopy. This study is part of a therapeutic evaluation and prognosis of this pathology in urology department of teaching university hospital (CNHUHKM) at Cotonou-Benin.

\section{Methods}

In this study, a retrospective and descriptive, covering a period of six months, running from January 1st to December 31st, 2013 was conducted to evaluate therapeutic and prognosis of Uretero-pelvic junction abnormalities. Included criteria were all patients whose the diagnosis of UPJ abnomalities had been confirmed after para clinical exploration. The stricture of the junction as a recurrence after a first kidney surgery did not included. We have found 69 cases. The creatinine level has considered high from $15 \mathrm{mg} / \mathrm{l}$. The following items studied: age, sex, occupation, Clinical examination findings at presentation, the therapeutic management and the postoperatives complications. The Data were processed with Epi-info 3.5.4 software.

\section{Results}

The median age was 35 years old [range: 10 years and 85 years]. Age groups risk was [30 - 40] years old in $36.2 \%$ (Figure 1). A male predominance had been noted in $62.3 \%$ against $37.7 \%$ women. The sex ratio was 1.6. The most affected occupation was the officials in $37.7 \%$ (Table 1). The majority of patients have been sent from the peripheral centers to the urology department in $84.1 \%$. The average period of consultation was 2.21 years, ranging from 1day and 20 years. The most symptom of consutation was lumbar pain in $97.1 \%$ followed by digestive disorders, fever and urinary disconfort respectively in $26.1 \%, 17.4 \%$ and $15.9 \%$ of cases. Physical examination was poor but the lumbar mass was present in 9 patients (13\%) and the general poor condition in 8 cases (11.6\%).

The high creatinine level has been observed in 19 patients (27.5\%). The cytobacteriological examination has carried out by all our patients but it was positive in 17 cases (24.6\%) and Escherichia coli has been isolated in $41.2 \%$ of cases followed by Klesiella pneumoniae in $29.4 \%$.

Ultrasound findings uretero-pelvic junction obstructive (UPJO) in $49.2 \%$ of cases, extrinsic compression in $4.6 \%$ of cases and ureterohydronephrosis has been mentioned in $46.2 \%$ of cases predominantly at left side. However the intraveinous urography helped to objective an abnormality of the junction at the left in $51.7 \%$ cases; at right in $32.8 \%$ of cases and bilateral in $15.5 \%$ of cases.

The proportion of patients who underwent surgery was $88.41 \%$ (61 cas). An abstention has been observed in 7 patients (10.1\%) and one patient died before the surgical management by renal failure (see Table 2). However in

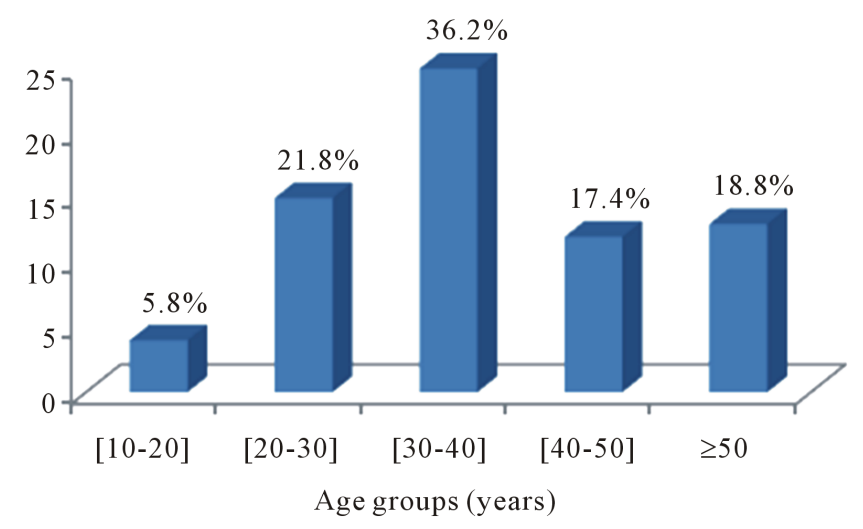

Figure 1. Distribution the patients by age groups. 
preoperative time $8.7 \%$ (6 cas) had had a nephrostomy before the pyeloplasty. $43.5 \%$ (30 cas) had had nephrolithomy addition pyeloplasty.

In intraoperative time, the etiologies found were: UJPO in $85.48 \%$ (53 cas); vessel crossing pole pitch in $6.45 \%$ ( 4 cas); fribrous flange in 1.61 of cases ( 1 cas); retroperitoneal lymph nodes in $6.45 \%$ ( 4 cas).

The length port of the renal drain lodge had been 9.4 days. The early postoperative course have been uneventful in $78.7 \%$ (48 cases) and complicated in $21.3 \%$ (21 cases). The most common postoperative complications have been the ureteral skin fistula (see Table 3). Its evolution has been normal during hospitalization. There has had one case of secondary stenosis which was taken for a new plasty. The average hospital stay was 16.62 days [range: 2 days and 86 days].

Table 1. Distribution the patient by profession.

\begin{tabular}{ccc}
\hline Profession & Number & Percentage (\%) \\
\hline Officials & 26 & 37.7 \\
Housewife & 8 & 11.6 \\
Pupil/Student & 10 & 14.5 \\
Dealer & 11 & 15.7 \\
Craftsman & 8 & 11.6 \\
Conductor & 3 & 4.4 \\
Cultivator & 3 & 4.4 \\
Total & 69 & 100 \\
\hline
\end{tabular}

Table 2. Surgical management.

\begin{tabular}{ccc}
\hline Technique & Number & Percentage (\%) \\
\hline Abstention & 7 & 10.3 \\
Pyeloplasty by Hynes-Anderson-Kuss & 49 & 72.0 \\
Pyeloplasty by Y-V & 5 & 7.4 \\
Nephrectomy & 2 & 2.9 \\
Flange Section & 1 & 1.5 \\
Decrease Vascular & 4 & 5.9 \\
Total & 68 & 100 \\
\hline
\end{tabular}

Table 3. Distribution the patients by the complications types.

\begin{tabular}{ccc}
\hline Complications & Number & Percentage (\%) \\
\hline Ureteral skin fistula & 7 & 53.8 \\
Ureteral stenosis & 1 & 7.7 \\
Lumbar pain & 2 & 15.4 \\
Hematuria & 1 & 7.7 \\
Impaired renal failure & 2 & 15.4 \\
Total & 13 & 100 \\
\hline
\end{tabular}




\section{Discussion}

The average age of discovery of the UJPO has undergone major changes in recent years thanks to the progress of prenatal diagnosis. Congenital pathology, the abnormalities of ureteropelvic junction have been discovered most often in young adults in the 3rd and 4th decade [2]. Such is the case in our study where the median age of diagnosis was 35 years. This is stackable on those of the majority of African studies [3]-[5] where the average age was 32, 6 years unlike the series of European and American countries where almost all of the anomalies of the junction have discovered and treated early thanks the prenatal diagnosis [6]-[9]. In these developed countries, this can be explained by the ease of the completion of the antenatal ultrasound during pregnancy and especially on monitoring this anomaly upon detection. This especially monitoring offers little in our African countries where there is a limitation of resources. Also it exists in these countries advanced technology that is not always the case in Third World countries such as ours. Most authors report a male predominance with a sex ratio ranging from 1.40 to 1.8 [2] [3] [8] [10]. These results are stackable on that of the study where the sex ratio is 1.62. In this study the most occupation affected was the officials in $37.7 \%$ of cases. This is justified firstly by the fact that they come to consult frequently early and they also enjoy the benefits of the care related to their social status, unlike others occupations. Discover mode in developing countries of this anomaly is by antenatal ultrasound but such is not the case in this study where the mode of discovery was lumbar pain in $97.1 \%$ of cases and also in many others African countries [3] [5]. The main exams for diagnosis had been the abdominal pelvic ultrasound and intraveinous urography. They have in addition to the revelation of the abnormality of the pelvic junction urinary lithiasis. The contribution of ultrasonography lies mainly in the prenatal diagnosis of abnormality of the ureteropelvic junction. Obstetric ultrasound has in fact completely transformed the classic presentation of this pathology. It enables the diagnosis and early treatment of the disease [6].

As for the management of patients the technical of Hynes-Anderson-Kuss has been used in $72 \%$ of cases for the pyeloplasty. However, two nephrectomies were performed for silent kidneys on intravenous urography , the computed tomography (CT) urography is not accessible to all social classes and especially scintigraphy is not available in our context for detecting the percentage of nephrons destroyed. The early postoperatives courses have been uneventful in 78.7\% (48 cases) as in the study of Kirakoya et al. [5] but this result is lower to the results of laparoscopy found by some authors who were respectively 88\%, 93\%, 3\% and 87.7\% of cases [11]-[13]. Traditionally open pyeloplasty has been the standard of care but minimally invasive surgical techniques have become increasingly popular. Endopyelotomy has a lower success rate than other modalities (42\% - 90\% depending on the approach), but is associated with reduced pain and shorter convalescence. Laparoscopic pyeloplasty and robot-assisted pyeloplasty have similar success rates to open pyeloplasty (>90\%), with the additional advantages of significantly reduced morbidity and shorter convalescence. More long-term outcome data for minimally invasive surgical techniques are awaited [14]. The length port of the renal lodge catheter had been 9.4 days, which is stackable on that of Kirakoya et al. [5]. However in their series a transanastomotic drain had been also placed [5]. 19 patients (27.5\%) were hospitalized with high creatinine level and two cases showed renal failure after pyeloplasty. According to Rivas et al. [15] laparoscopic pyeloplasty not only corrects the UJPO, but it also may recover renal function demonstrated after one year follow up with diuretic renography. Laparoscopic pyeloplasty should be procedure of choice even in those patients with poor renal function at diagnosis, whenever there are chances of recovering renal function, regardless patients age. The average hospital stay was 16.62 days stackable to that found by kirakoya et al. [5] which was 14 days who have used also open surgery. But it seems high compared to those of some authors [9] [15] which were 3.2 days and 3.6 days who have used the laparoscopy.

Limitations of this study include lack of long-term followed patients who do not return to consultation few months after operation. Then, Computer Tomography urography has not realized by patients because it was a bit expansive.

\section{Conclusion}

Abnormalities of the junction are a pathology whose therapeutic management is often difficult because of the persistance of postoperative hydronephrosis for years. This hydronephrosis can still compromise renal function. Open surgery tends to disappear at the expense of the endopyelotomy and laparoscopy which give best results. However, it is still relevant. 


\section{Conflict of Interest}

The authors declare that they have no conflict interest.

\section{References}

[1] Lacombe, M. (2000) Précis d'anatomie et de physiologie humaine. 28th Edition.

[2] Singh, V. and Sinha, R.J. (2011) Laparoscopic Dismembered Pyeloplasty and Pyelolithotomy in a Patient with a Retrocaval Ureter. Urology Journal, 8, 231-235.

[3] Ibrahim, A.G., Aliyu, S. and Ali, N. (2014) Bilateral Pelvi-Ureteric Junction Obstruction : Our Experience in a Developing Country. Nigerian Journal of Clinical Practice, 17, 267-269. http://dx.doi.org/10.4103/1119-3077.130205

[4] Arap, M.A., Torricelli, F.C., Mitre, A.I., Chambo, J.L., Duarte, R.J. and Srougi, M. (2013) Lessons from 90 Consecutive Laparoscopic Dismembered Pyeloplasties in a Residency Program. Scandinavian Journal of Urology, 47, 323-327. http://dx.doi.org/10.3109/00365599.2012.740071

[5] Kirakoya, B., Kabore, F.A., Zango, B., Pare, A.K., Yameogo, C. and Kambou, T. (2015) Management of Ureteropelvic Junction Obstruction at the Urology Department of University Hospital Yalgado Ouedraogo (Burkina Faso). Uro'Andro, 1, 148-152.

[6] Liu, D.B., Armstrong 3rd, W.R. and Maizels, M. (2014) Hydronephrosis: Prenatal and Postnatal Evaluation and Management. Clinics in Perinatology, 41, 661-678. http://dx.doi.org/10.1016/j.clp.2014.05.013

[7] Turner 2nd, R.M., Fox, J.A., Tomaszewski, J.J., Schneck, F.X., Docimo, S.G. and Ost, M.C. (2013) Laparoscopic Pyeloplasty for Ureteropelvic Junction Obstruction in Infants. Journal of Urology, 189, 1503-1507. http://dx.doi.org/10.1016/j.juro.2012.10.067

[8] Moreira-Pinto, J., Osório, A., Vila, F., Luís, J., de Castro, J.R. and Réis, A. (2012) Dismembered Pyeloplasty for Ureteropelvic Junction Syndrome Treatment in Children. African Journal of Paediatric Surgery, 9, 98-101. http://dx.doi.org/10.4103/0189-6725.99392

[9] Blanc, T., Koulouris, E., Botto, N., Paye-Jaouen, A. and El-Ghoneimi, A. (2014) Laparoscopic Pyeloplasty in Children with Horseshoe Kidney. Journal of Urology, 191, 1097-1103. http://dx.doi.org/10.1016/j.juro.2013.10.059

[10] Buffi, N.M., Lughezzani, G., Fossati, N., Lazzeri, M., Guazzoni, G., Lista, G., Larcher, A., Abrate, A., Fiori, C. and Cestari, A.P.F. (2014) AND Robot-Assisted, Single-Site, Dismembered Pyeloplasty for Ureteropelvic Junction Obstruction with the New da Vinci Platform: A Stage 2a Study. European Urology, 38, 210-213.

[11] Subotic, S., Weiss, H., Wyler, S., Rentsch, C.A., Rassweiler, J., Bachmann, A. and Teber, D. (2013) Dismembered and Non-Dismembered Retroperitoneoscopic Pyeloplasty for the Treatment of Ureteropelvic Junction Obstruction in Children. World Journal of Urology, 31, 689-695. http://dx.doi.org/10.1007/s00345-012-0887-0

[12] Abraham, G.P., Siddaiah, A.T., Ramaswami, K., George, D. and Das, K. (2015) Laparoscopic Management of Recurrent Ureteropelvic Junction Obstruction Following Pyeloplasty. Urology Annals, 7, 183-187. http://dx.doi.org/10.4103/0974-7796.150489

[13] Seo, I.Y., Oh, T.H. and Lee, J.W. (2014) Long-Term Follow-Up Results of Laparoscopic Pyeloplasty. Journal of Urology, 55, 656-659. http://dx.doi.org/10.4111/kju.2014.55.10.656

[14] Khan, F., Ahmed, K., Lee, N., Challacombe, B., Khan, M.S. and Dasgupta, P. (2014) Management of Ureteropelvic Junction Obstruction in Adults. Nature Reviews Urology, 11, 629-638. http://dx.doi.org/10.1038/nrurol.2014.240

[15] Rivas, J.G., Gregorio, S.A., Eastmond, M.P., Gómez, A.T., Togores, L.H., Sebastián, J.D. and Barthel, J.J. (2014) Renal Function Recovery after Laparosocopic Pyeloplasty. Central European Journal of Urology, 67, 210-213. http://dx.doi.org/10.5173/ceju.2014.02.art22 